\title{
Sub-lethal doses of albendazole induce drug metabolizing enzymes and increase albendazole deactivation in Haemonchus contortus adults
}

Pavlína Kellerová1, Lucie Raisová Stuchlíková1, Petra Matoušková1, Karolína Štěrbová', Jiří Lamka², Martina Navrátilová1, Ivan Vokřál'², Barbora Szotáková and Lenka Skálovál* (i)

\begin{abstract}
The efficacy of anthelmintic therapy of farm animals rapidly decreases due to drug resistance development in helminths. In resistant isolates, the increased expression and activity of drug-metabolizing enzymes (DMEs), e.g. cytochromes P450 (CYPs), UDP-glycosyltransferases (UGTs) and P-glycoprotein transporters (P-gps), in comparison to sensitive isolates have been described. However, the mechanisms and circumstances of DMEs induction are not well known. Therefore, the present study was designed to find the changes in expression of CYPs, UGTs and P-gps in adult parasitic nematodes Haemonchus contortus exposed to sub-lethal doses of the benzimidazole anthelmintic drug albendazole (ABZ) and its active metabolite ABZ-sulfoxide (ABZSO). In addition, the effect of ABZ at sub-lethal doses on the ability to deactivate $A B Z$ during consequent treatment was studied. The results showed that contact of $H$. contortus adults with sub-lethal doses of $A B Z$ and $A B Z S O$ led to a significant induction of several DMEs, particularly cyp-2, cyp-3, cyp-6, cyp-7, cyp-8, UGT10B1, UGT24C1, UGT26A2, UGT365A1, UGT366C1, UGT368B2, UGT367A1, UGT371A1, UGT372A1 and pgp-3, pgp-9.1, pgp-9.2, pgp-10. This induction led to increased formation of ABZ metabolites (especially glycosides) and their increased export from the helminths' body into the medium. The present study demonstrates for the first time that contact of $\mathrm{H}$. contortus with sub-lethal doses of $A B Z$ (e.g. during underdose treatment) improves the ability of $H$. contortus adults to deactivate $A B Z$ in consequent therapy.
\end{abstract}

Keywords: drug resistance, anthelmintics, benzimidazoles, nematode, UDP-glycosyl transferases, cytochromes P450, P-glycoprotein, ABC-transporters

\section{Introduction}

Haemonchosis is one of the most important parasitic diseases of small ruminants. The nematode Haemonchus contortus (H. contortus), blood-feeding parasite in abomasum, has a broad range of host species, frequent and cosmopolitan geographic distribution, as well as a

*Correspondence: lenka.skalova@faf.cuni.cz

${ }^{1}$ Department of Biochemical Sciences, Faculty of Pharmacy, Charles University, Heyrovského 1203, 50005 Hradec Králové, Czech Republic

Full list of author information is available at the end of the article significant impact on livestock production. When the environmental conditions support the free-living larval stages, a heavy burden of adult helminths may occur in the hosts, leading to severe anemia which may result in death of animals $[1,2]$. Appropriate pasture management should be a primary way to control haemonchosis, but this type of prevention is not sufficient in many cases. In spite of the advances in vaccination development [3], anthelmintic drugs are still the most important tool in the prophylaxis and treatment of $H$. contortus infection in grazing sheep [4]. The efficacy of anthelmintic therapy,

c) The Author(s) 2020. This article is licensed under a Creative Commons Attribution 4.0 International License, which permits use, sharing, adaptation, distribution and reproduction in any medium or format, as long as you give appropriate credit to the original author(s) and the source, provide a link to the Creative Commons licence, and indicate if changes were made. The images or other third party material in this article are included in the article's Creative Commons licence, unless indicated otherwise in a credit line to the material. If material is not included in the article's Creative Commons licence and your intended use is not permitted by statutory regulation or exceeds the permitted use, you will need to obtain permission directly from the copyright holder. To view a copy of this licence, visit http://creativeco mmons.org/licenses/by/4.0/. The Creative Commons Public Domain Dedication waiver (http://creativecommons.org/publicdomain/ zero/1.0/) applies to the data made available in this article, unless otherwise stated in a credit line to the data. 
however, decreases due to drug-resistance development in helminths, with the helminths' high fertility and short generational interval providing an enviable developmental plasticity in terms of adaptation and the fast development of drug resistance in $H$. contortus [1]. Among the many mechanisms of drug resistance, some are based on the increased expression and activity of drug-metabolizing enzymes (DME) $[5,6]$. These proteins protect all organisms against the potential negative action of drugs and other xenobiotics, which can be metabolized (in series or independently) by three processes, termed Phase I to Phase III. In brief, Phase I enzymes add or uncover a polar group (e.g. hydroxyl group, amino group), while in Phase II a xenobiotic and/or its metabolite is conjugated with an endogenous component such as glucose or glutathione in order to reduce reactivity and usually to increase solubility. In Phase III, xenobiotics and/or their metabolites are transported across membranes to facilitate their biotransformation and elimination [6].

Nematodes possess a relatively large number of DME genes, much higher than other helminth classes [6]. Owing to this fact, nematodes are able to effectively metabolize many anthelmintics and form various types of anthelmintic metabolites [7, 8]. Moreover, drug-resistant nematodes have been shown to form higher amounts of inactive metabolites than did drug-sensitive nematodes [8-10]. It has become clearer that DMEs play an important role in drug resistance in nematodes. From this point of view, three DME super-families attract particular attention: cytochromes P450 (CYPs), UDP-glycosyltransferases (UGTs) and ATP-binding cassette (ABC) transporters. CYPs are the main enzymes catalyzing Phase I of drug metabolism, particularly drug oxidation. In $H$. contortus, constitutive expression is highest in the larval stages for the majority of CYPs, although the pronounced expression of many CYPs was also detected in the adults, especially in the helminth intestine [11].

Thirty-two isoforms of UGTs, the most important Phase II enzymes catalyzing conjugation of UDP-activated sugar donors to small lipophilic chemicals, were identified in $H$. contortus genome. Constitutive expression of isoform UGT368B2 was significantly higher in $H$. contortus resistant strains than in the sensitive strains [12].

$A B C$ transporters are implicated in the transport of a variety of drugs and other xenobiotics across cellular membranes. The participation of several ABC transporters in drug resistance, particularly P-glycoproteins (P-gps), have been described in many parasites [13]. A recent study evaluated the increased expression of P-gp genes in a highly-resistant isolate of $H$. contortus [14].

Although many studies, including the studies mentioned above, have demonstrated the increased expression of some DMEs in resistant isolates in comparison to sensitive ones, many questions remain unanswered. For example, the mechanisms and circumstances under which this increase in expression occurs is not well known. We hypothesize that the induction of certain DMEs in $H$. contortus via contact with sub-lethal doses of anthelmintics which occurs during inaccurate treatment might play important role. Therefore, the present ex vivo study was designed to evaluate the effect of the benzimidazole anthelmintic drug albendazole (ABZ) and its active metabolite ABZ-sulfoxide (ABZSO, the main compound in plasma of ABZ-treated animals) at sublethal doses on the expression of CYPs, UGTs and P-gps in adults of $H$. contortus. In addition, the effect of $A B Z$ at sub-lethal doses on the ability to deactivate ABZ during consequent exposure was studied with the aim of determining not only the transcriptional response but also the functional response to anthelmintics.

\section{Materials and methods \\ Parasites}

In this ex vivo study we used a susceptible isolate of $H$. contortus ISE: the inbred susceptible-Edinburgh strain (MHco3) [15]. Five lambs 3-4 months old and free of parasites were orally infected with 6000 third stage larvae (L3) of the $H$. contortus ISE strain. Approximately 7 weeks after infection the animals were stunned and exsanguinated in agreement with Czech slaughtering rules for farm animals and according to the protocols which have been evaluated and approved by the Ethics Committee of the Ministry of Education, Youth and Sports (Protocol MSMT-25908/2014-9). The agar method was used to isolate the adult nematodes from the sheep hosts' abomasum [16]. The time between the death of the animal and the isolation of helminths did not exceed $2 \mathrm{~h}$. The live parasites were washed with phosphate-buffered saline ( $\mathrm{pH}$ 7.4) (PBS) and manually divided by gender based on morphology.

\section{The exposure of adults to anthelmintics}

Males and females were placed separately into RPMI 1640 media (Sigma-Aldrich, Prague, Czech Republic). For transcriptomic analysis, the adults were split into seven groups ( 3 sample parallels, 10 females or 15 males per sample to obtain sufficient and comparable amount of RNA or proteins) and incubated in $2 \mathrm{~mL}$ RPMI medium with or without the drug at $37{ }^{\circ} \mathrm{C}$ in $\mathrm{CO}_{2} / \mathrm{O}_{2}$ incubator $\left(5 \% \mathrm{CO}_{2}\right.$, at dark). Three groups were exposed to different concentrations of $\mathrm{ABZ}(0.01 \mu \mathrm{M}, 0.1 \mu \mathrm{M}$, $1 \mu \mathrm{M})$, three another groups were exposed to different concentrations of ABZSO $(0.01 \mu \mathrm{M}, 0.1 \mu \mathrm{M}, 1 \mu \mathrm{M})$, and one group was placed into medium only with $0.1 \%$ dimethyl sulfoxide (DMSO, solvent) as a control. All 
groups exposed to $A B Z$ were subsequently exposed to $0.1 \%$ DMSO. A stock solution of $1 \mathrm{mM} \mathrm{ABZ}$ and ABZSO (Sigma-Aldrich, Prague, Czech Republic) was prepared in DMSO followed by serial dilutions in DMSO to produce 3 separate stock concentrations $(10 \mu \mathrm{M}, 100 \mu \mathrm{M}$ and $1000 \mu \mathrm{M})$. The incubations lasted 4 and $12 \mathrm{~h}$. In all the groups, the nematodes were alive (based on motility check) during all incubations regardless of whether $\mathrm{ABZ}$ was present or absent in the medium. After 4-h and 12 -h exposure, the nematodes were immediately placed into $1 \mathrm{~mL}$ TriReagent ${ }^{\circledR}$ (Molecular Research Centre, OH, USA), and stored at $-80^{\circ} \mathrm{C}$ for later use.

For functional analysis (summarized in Table 1), the nematodes (males and females separately, 4 sample parallels, 10 females or 15 males per sample) were pre-incubated in $2 \mathrm{~mL}$ medium without ABZ (control group) or with $\mathrm{ABZ}$ at $0.01,0.1$ and $1.0 \mu \mathrm{M}$ concentrations (affected groups) for $18 \mathrm{~h}$. After pre-incubations, the nematodes were manually washed in PBS twice and placed in fresh medium for incubation. First parallels (blanks) of each group were placed into the medium without $\mathrm{ABZ}$, and second, third and fourth parallels into the medium with $10 \mu \mathrm{M} \mathrm{ABZ}$ (the standard concentration of $\mathrm{ABZ}$ for metabolism studies which does not kill nematodes $[8,10,17])$ and incubated for $12 \mathrm{~h}$. After incubation, the nematodes were washed twice in PBS, with both the nematodes and medium separately inserted in microtubes and stored in a freezer $\left(-20{ }^{\circ} \mathrm{C}\right)$. This experiment was repeated twice.

\section{RNA extraction and CDNA synthesis}

Total RNA was extracted using TriReagent ${ }^{\circledR}$ according to the manufacturer's protocol following the homogenization of the samples in the FastPrep-24 5G Homogenizer (MP Biomedicals, France). RNA concentrations and purity were determined spectrophotometrically using the NanoDrop ND-1000 UV-Vis Spectrophotometer (Thermo Fisher Scientific, MA, USA) at a wavelength of 260 and $280 \mathrm{~nm}$. The samples were analyzed by the Agilent 2100 Bioanalyzer on RNA Nano chips (Agilent Technologies, CA, USA). Four $\mu \mathrm{g}$ of RNA were treated with DNase I (NEB, UK) and diluted to a concentration of $0.1 \mu \mathrm{g} / \mu \mathrm{L}$. One half microgram of the total RNA, random hexamers and Protoscript ${ }^{\circledR}$ II Reverse Transcriptase (NEB, UK) were used for reverse transcription (in $20 \mu \mathrm{L}$ reaction mixture) according to the manufacturer's protocol, following which the obtained cDNA was diluted $10 \times$ and stored at $-20^{\circ} \mathrm{C}$.

\section{Quantitative PCR (qPCR)}

The changes in expression of the selected CYPs, UGTs and P-gps in $H$. contortus were analyzed by qPCR analyses performed in the 384-Well PCR Thermal Cycler; QuantStudio $^{\mathrm{TM}} 6$ Flex Real-Time PCR System (Applied Biosystems, CA, USA) with SYBR Green I detection. Approximately $5 \mathrm{ng}$ of cDNA was added into a reaction mixture consisting of qPCR Xceed SG 1-step $2 \times$ Mix Lo-ROX (IAB, Czech Republic), both forward and reverse primers (final concentration $100 \mathrm{nM}$ ), in a final volume of $6 \mu \mathrm{L}$. The PCR cycling conditions were initiated by a denaturation step of $2 \mathrm{~min}$ at $95{ }^{\circ} \mathrm{C}$, followed by 40 cycles of two step amplification as follows: denaturation for $15 \mathrm{~s}$ at $95{ }^{\circ} \mathrm{C}$, annealing for $30 \mathrm{~s}$ at $60{ }^{\circ} \mathrm{C}$. Fluorescence data were acquired during the last step. A dissociation protocol with a gradient $\left(0.5^{\circ} \mathrm{C}\right.$ every $\left.30 \mathrm{~s}\right)$ from 65 to $95{ }^{\circ} \mathrm{C}$ was used to investigate the specificity of the qPCR reaction and presence of primer dimers. Gene-specific amplification was confirmed by a single peak in the melting curve analysis. Samples were run in three biological and two technical replicates, with relative expression calculated based on the "Delta-Delta Ct method" [18]. Two housekeeping genes, glyceraldehyde-3P-dehydrogenase (gpd) and nuclear-cap binding protein subunit 2-like (ncbp), were used as reference genes for the qPCR assay [19]. The primer sequences were either used as previously published or newly designed in Primer3 software [20] with predicted melting temperature $60 \pm 2{ }^{\circ} \mathrm{C}$, lengths of 20-23 nucleotides (nt) and GC contents of $>45 \%$. Each gene was checked by Mfold at $60{ }^{\circ} \mathrm{C}$ [21] to avoid the region of hairpin structure. All primer sequences were synthesized by Generi Biotech, Czech Republic. The specificity and

Table 1 Experimental design of functional analysis

\begin{tabular}{|c|c|c|c|c|c|c|c|}
\hline & \multicolumn{4}{|c|}{ Pre-incubation $18 \mathrm{~h}$} & & \multicolumn{2}{|c|}{ Incubation $12 \mathrm{~h}$} \\
\hline & Control & Affected & & & & Control & Affected \\
\hline Blanks & DMSO 0.1\% & $0.01 \mu \mathrm{M}$ ABZ & $0.1 \mu \mathrm{M}$ ABZ & $1.0 \mu \mathrm{M} \mathrm{ABZ}$ & WASHING & DMSO 0.1\% & DMSO 0.1\% \\
\hline 1 & DMSO 0.1\% & $0.01 \mu \mathrm{M}$ ABZ & $0.1 \mu \mathrm{M}$ ABZ & $1.0 \mu \mathrm{M} \mathrm{ABZ}$ & & $10 \mu \mathrm{M} \mathrm{ABZ}$ & $10 \mu \mathrm{M}$ ABZ \\
\hline 2 & DMSO 0.1\% & $0.01 \mu \mathrm{M}$ ABZ & $0.1 \mu \mathrm{M}$ ABZ & $1.0 \mu \mathrm{M}$ ABZ & & $10 \mu \mathrm{M} \mathrm{ABZ}$ & $10 \mu \mathrm{M} \mathrm{ABZ}$ \\
\hline 3 & DMSO 0.1\% & $0.01 \mu \mathrm{M}$ ABZ & $0.1 \mu \mathrm{M}$ ABZ & $1.0 \mu \mathrm{M}$ ABZ & & $10 \mu \mathrm{M} A B Z$ & $10 \mu \mathrm{M} \mathrm{ABZ}$ \\
\hline
\end{tabular}

Affected groups of helminths were pre-incubated with sub-lethal concentrations of ABZ $(0.01,0.1$ and $1.0 \mu \mathrm{M})$ for $18 \mathrm{~h}$. Control groups were pre-incubated with no ABZ. Both affected and control groups were followingly incubated with high $A B Z$ concentration $(10 \mu \mathrm{M})$ for $12 \mathrm{~h}$ except the blanks. 
efficiency of the primers were checked for the qPCR conditions used. The primer sequences, amplicon sizes, and efficiencies are listed in Additional file 1.

\section{Analysis of $A B Z$ and its metabolites}

The adult nematodes (female and male separately) were homogenized repeatedly six-times for $30 \mathrm{~s}$ in cooled 0.1 M phosphate buffer ( $\mathrm{pH}$ 7.4) using the FastPrep homogenizer, after which the homogenates were centrifuged at $3000 \times g$ for $5 \mathrm{~min}$. The concentration of protein in the homogenates of the nematodes was measured using a bicinchoninic acid assay according to Sigma-Aldrich protocols. Supernatants of the homogenates as well as medium samples were extracted using solid-phase extraction (SPE) as described previously [22]. Dry samples were quantitatively reconstituted in a mixture of acetonitrile/water $(30: 70, v / v)$ using sonication and a vortex for $5 \mathrm{~min}$.

One microliter of the reconstituted samples was injected into the UHPLC/MS system. UHPLC (Nexera; Shimadzu, Japan) was optimized using a Zorbax RRHD Eclipse Plus 95Å C18 column $150 \times 2.1 \mathrm{~mm}$, $1.8 \mu \mathrm{m}$ (Agilent Technologies, Waldrbronn, Germany) at a temperature of $40{ }^{\circ} \mathrm{C}$, flow rate $0.4 \mathrm{~mL} / \mathrm{min}$ and injection volume $1 \mu \mathrm{L}$. The mobile phase consisted of water (A) and acetonitrile (B), both with the addition of $0.1 \%$ formic acid (MS grade). The linear gradient was as follows: $0 \mathrm{~min}-15 \% \mathrm{~B}, 8 \mathrm{~min}-40 \% \mathrm{~B}, 10 \mathrm{~min}-95 \%$ $B$ followed by 1 min of isocratic elution. The QqQ mass spectrometer (LC-MS-8030 triple quadrupole mass analyzer; Shimadzu, Japan) was used with the following setting of tuning parameters: capillary voltage $4.5 \mathrm{kV}$, heat block temperature $400{ }^{\circ} \mathrm{C}$, DL line temperature $250{ }^{\circ} \mathrm{C}$, the flow rate and pressure of nitrogen were $12 \mathrm{~L} / \mathrm{min}$, respectively. ESI mass spectra were recorded in the range of $m / z 50-1000$ in the positive-ion mode, a greater sensitivity for the studied metabolites. The detected metabolites were identified based on the presence of the protonated molecules $[\mathrm{M}+\mathrm{H}]^{+}$. The isolation width $\Delta m / z 2$ and the collision energy $25 \mathrm{eV}$ (determined as the optimal energy for fragmentation of the studied metabolite ions) were used. Argon was the collision gas for MS/MS experiments. The standards of the potential metabolites were generally not commercially available, and they were not prepared due to the difficulties involved in their synthesis. For this reason, the amounts of metabolites were semi-quantified using a ratio of peak areas for the metabolites, with the area of the internal standard (IS) peak (mebendazole). In the homogenates of the nematodes, these ratios were normalized to a milligram of total protein. All data are presented as arithmetic mean \pm S.D. $(n=4)$.

\section{Statistical analysis}

The data for statistical analysis were expressed as the mean \pm S.D. (3 biological replicates of each sample for gene expression and 4 biological replicates for functional analysis, each replicate consisted of 10 females or 15 males). Gene expression differences between the treatment groups and incubation times were determined using a two-way ANOVA with Dunnett's multiple comparisons test. Statistical comparisons of the ABZ metabolites were carried out using the Student's t-test. All statistical tests were performed in GraphPad Prism ${ }^{\circledR}$ software 8.0.1 (GraphPad Prism, USA), with differences considered significant at $\mathrm{P}^{<} 0.05$.

\section{Results}

Transcriptional response of CYPs to exposure to sub-lethal concentrations of $A B Z$ and $A B Z S O$ in $H$. contortus adults

The expression levels of 8 individual CYPs (Wormbase ID numbers are listed in Additional file 1: Table S1) in control nematodes (females and males separately) and in nematodes exposed to sub-lethal concentrations of $\mathrm{ABZ}$ and ABZSO for 4 and $12 \mathrm{~h}$ were analyzed and compared. The exposures of $H$. contortus adults to sub-lethal ABZ concentrations significantly changed the mRNA expression of only three of the studied CYPs (Figure 1). Cyp-2 in females, cyp-3 and cyp-7 in males were significantly decreased after 4-h ABZ exposure. However, cyp7 in females (exposed to $1 \mu \mathrm{M} \mathrm{ABZ}$ ) and cyp-3 in males (exposed to 0.1 and $1 \mu \mathrm{M} \mathrm{ABZ}$ ) were up-regulated twice as much compared to control after 12-h ABZ exposure (at $0.1 \mu \mathrm{M}$ and $1 \mu \mathrm{M}$ concentrations). Sub-lethal doses of ABZSO affected expression of more CYPs genes then did ABZ. Four-hour exposure to ABZSO significantly increased expression of $c y p-2$ and $c y p-8$ in both genders, and cyp-4, cyp-6, cyp-7 and cyp-8 in males. However, only 2 genes, cyp-5 in females and cyp-8 in males, were up-regulated after 12-h ABZSO exposure. The induction effect was mild and only at one concentration and oneincubation time in most cases. In females, $1 \mu \mathrm{M}$ ABZSO induced cyp-2 (4-h exposure) and cyp-5 (12-h exposure), while $0.1 \mu \mathrm{M}$ ABZSO induced cyp-8 (4-h exposure) and cyp-5 (12-h exposure). In males, 4-h exposure increased expression of cyp-1, cyp-2, cyp-7 (all genes at $0.1 \mu \mathrm{M}$ ABZSO), cyp-4, cyp-8 (both genes at $0.01 \mu \mathrm{M}$ ABZSO) and cyp- 6 (at 0.01 and $1 \mu \mathrm{M} \mathrm{ABZSO}$ ).

\section{Transcriptional response of UGTs to exposure to sub-lethal concentrations of $A B Z$ and $A B Z S O$ in $\mathrm{H}$. contortus adults}

The expression of UGT genes in control $H$. contortus adults and in adults exposed to sub-lethal concentrations of $\mathrm{ABZ}$ and $\mathrm{ABZSO}$ for 4 and $12 \mathrm{~h}$ were analyzed. After 4-hour ABZ exposure, expression of UGT365A1, 


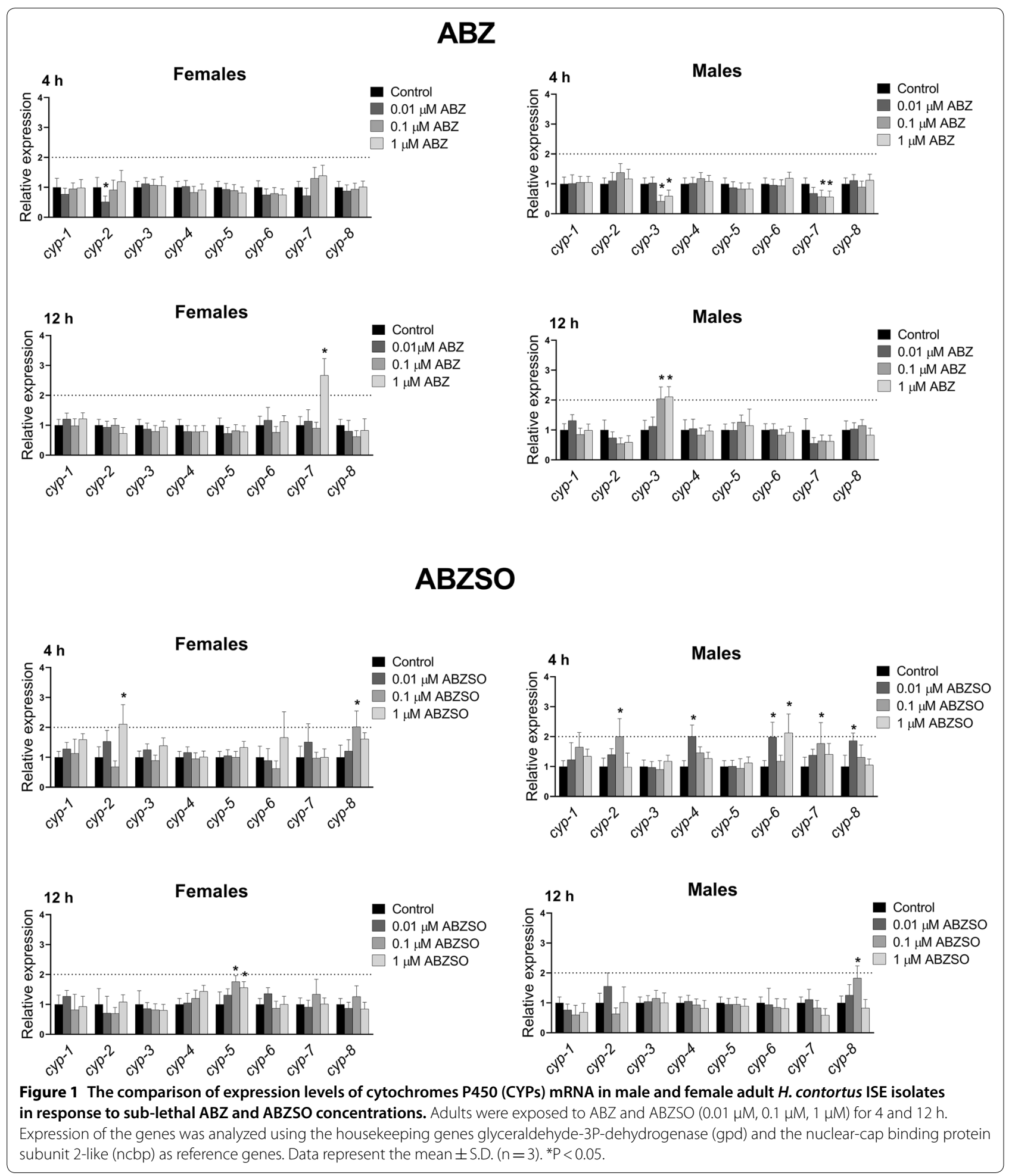

UGT367A1 and UGT368B2 was elevated in females (Figure 2). UGT1OB1 and UGT367A1 showed increased expression in females exposed to ABZ for 12-h. Interestingly, $\mathrm{ABZ}$ at all three concentrations and both time intervals showed substantially and highly elevated UGT367A1 expression in the females (>4-times). In the males, expression of twelve UGT genes were changed after ABZ exposure (Figure 3). Seven genes were 


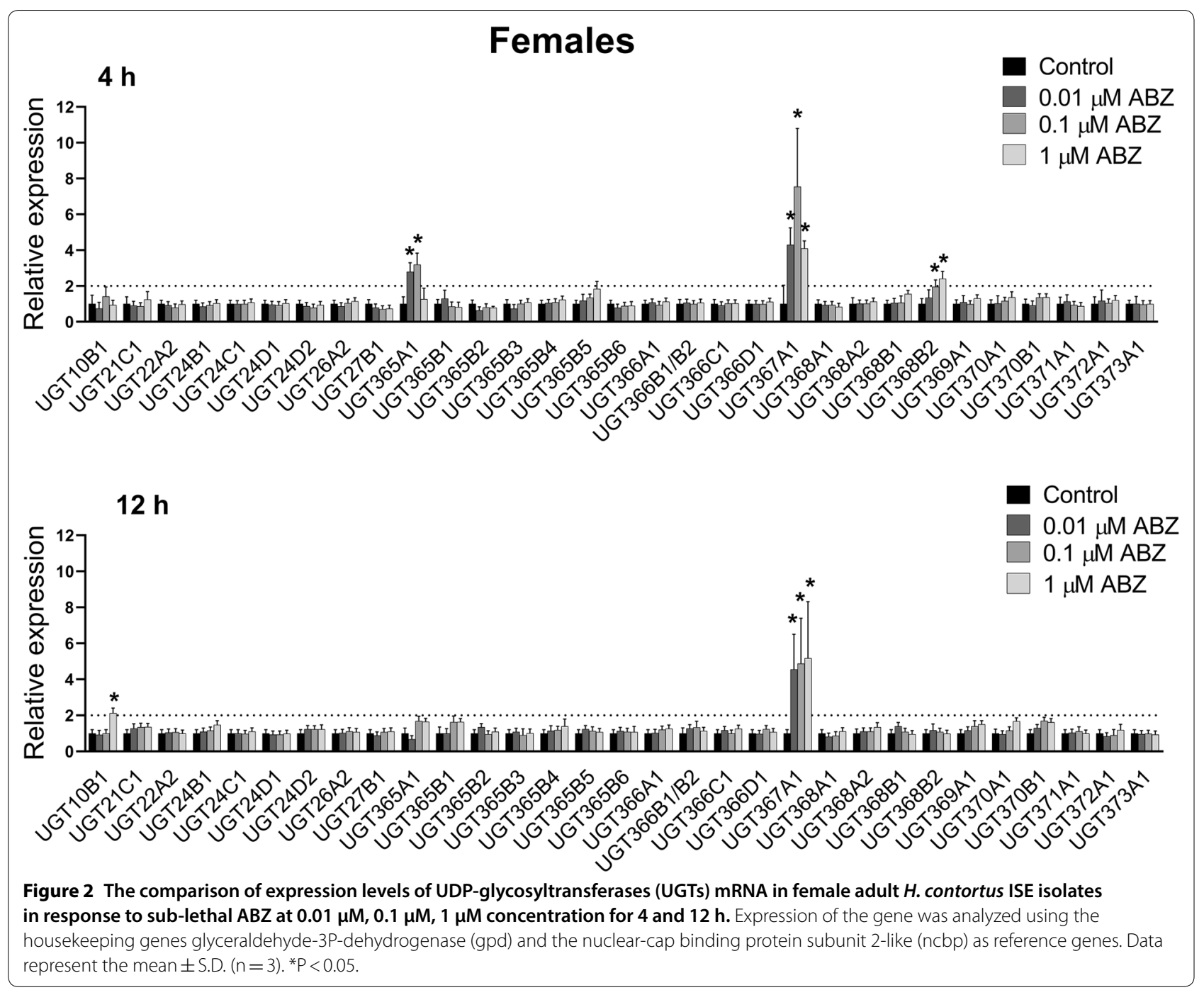

up-regulated after 4-h exposure: UGT26A2, UGT365A1, UGT365B3, UGT365B5, UGT368A2, UGT368B2, $U G T 371 A 1$, and two genes after 12-h exposure: UGT365B1 and UGT368B2. Transcription levels of six genes were mildly decreased: UGT10B1 and UGT365B1 after 4-h exposure, and UGT365A1, UGT365B6, UGT367A1 and UGT373A1 after 12-h exposure. In males, UGT26A2 seems to be the most interesting, as $\mathrm{ABZ}$ at all concentrations increased its expression.

In the females, ABZSO exposure induced UGT366A1 expression after both 4- and 12-h exposures (Figure 4). Whereas after 4-h exposure no other UGT gene had changed expression, increased expressions of 5 other UGT genes (UGT10B1, UGT24D1, UGT24D2, UGT366C1, UGT372A1) were observed after 12-h exposure. Induction of $U G T 10 B 1$ was the most pronounced, occurring at all ABZSO concentrations. In the males, ABZSO-induced overexpression of four UGTs was detected, with UGT372A1 being the most elevated after 4-h exposure (Figure 5). Expressions of five UGTs were up-regulated and two down-regulated after 12-h ABZSO exposure.

Transcriptional response of $\mathrm{P}$-gps to exposure to sub-lethal concentrations of $A B Z$ and $A B Z S O$ in $H$. contortus adults In our ex vivo study, exposure to $\mathrm{ABZ}$ and $\mathrm{ABZSO}$ affected transcription levels of six (out of eight tested) transporter genes in $H$. contortus adults (Figure 6). Concerning ABZ, a 4-h exposure of the females to all three concentrations resulted in significant up-regulation of pgp-9.2 expression in comparison to controls, but this increase dropped after $12-\mathrm{h}$ exposure significantly. However, a 4-h ABZ exposure in the males caused pgp-9.2 down-regulation, while $12-\mathrm{h} \mathrm{ABZ}$ exposure (all three concentrations) led to significant pgp-9.2 up-regulation. The other genes with induced levels after 12-h ABZ 


\section{Males}

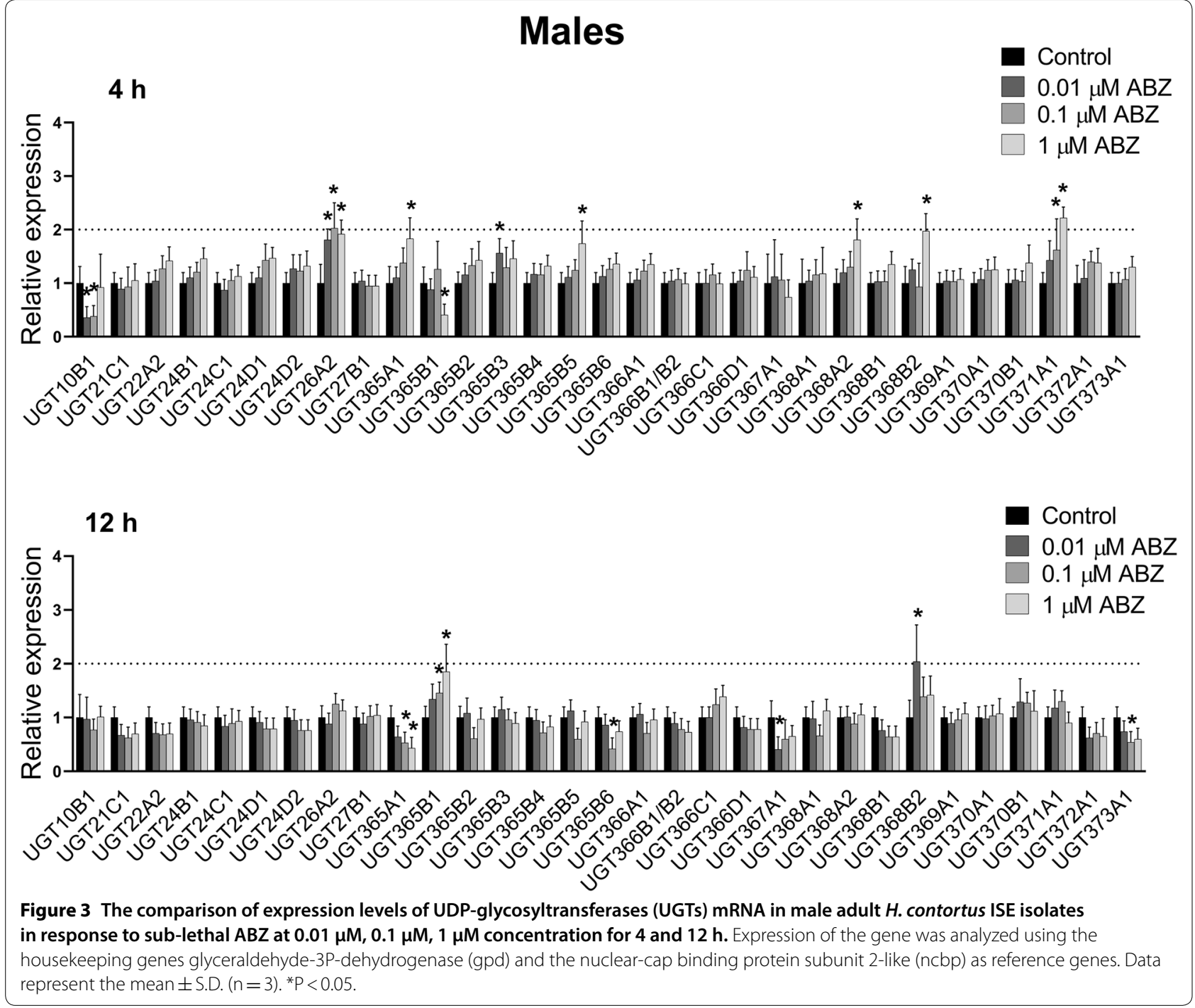

exposure were $p g p-9.1, p g p-10$ in the males and $p g p-16$ in the females. Concerning ABZSO, 4-h exposure increased $p g p-9.1$ in the females and pgp-16 in the males. The 12-h ABZSO exposure slightly increased pgp-3 in the females, and pgp-9.1, pgp-9.2 (both after $1 \mu \mathrm{M} \mathrm{ABZSO}$ ) and pgp13 (only after $0.1 \mu \mathrm{M}$ ABZSO) in the males.

\section{Effect of $A B Z$ at sub-lethal doses on $H$. contortus ability to metabolize ABZ}

The $H$. contortus adults were pre-incubated in medium without ABZ (control group) and with ABZ at 0.01, 0.1 and $1.0 \mu \mathrm{M}$ concentrations (affected groups) for $18 \mathrm{~h}$. The $H$. contortus adults were then placed in fresh medium without ABZ (blanks) or with $10 \mu \mathrm{M} \mathrm{ABZ}$ and incubated for $12 \mathrm{~h}$. Qualitative and semi-quantitative analyses of ABZ metabolites in homogenate from the nematodes and in medium was performed using UHPLC/MS. The metabolites were identified based on their fragmentation ions as described previously [10]. The designation and description of the metabolites is presented in Table 2. ABZ metabolites were formed via $S$-oxidation or hydroxylation, hydrolysis and glycosidation followed by $O$-acetylation.

The presence/absence of individual metabolites in the control samples (homogenate and medium from the nematodes pre-incubated in medium without ABZ), and the affected samples (homogenate and medium from the nematodes pre-incubated with $0.01,0.1$ and 1.0 $\mu \mathrm{M} \mathrm{ABZ)} \mathrm{is} \mathrm{summarized} \mathrm{in} \mathrm{Table} \mathrm{3.} \mathrm{Semi-quan-}$ tification allowed the comparison of the amounts of individual metabolites present in the homogenate and cultivation medium of male and female nematodes with or without pre-incubation, with the results shown in Figure 7. The scheme of metabolic pathway of ABZ 


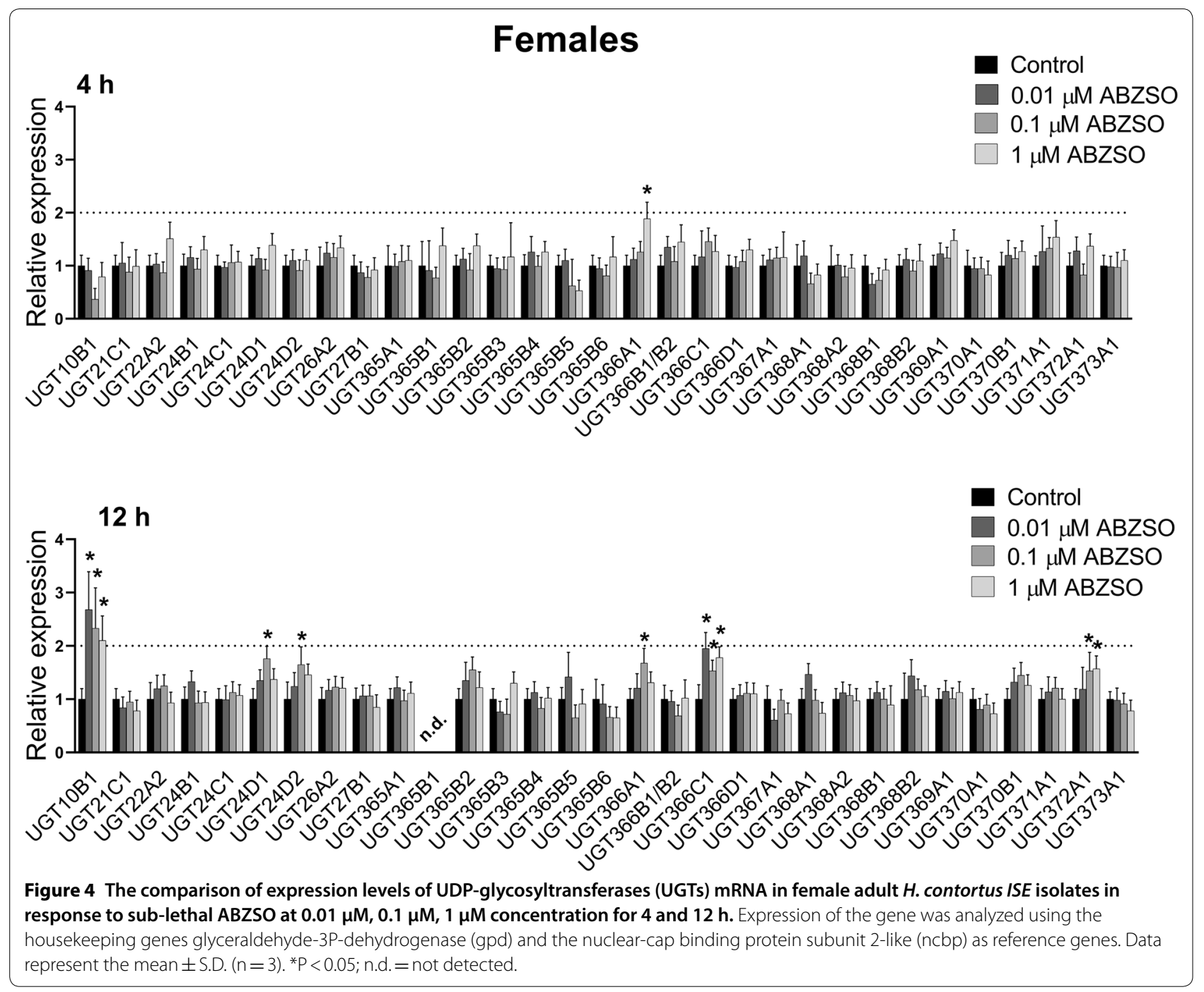

in $H$. contortus adults is presented in Figure 8. In the medium with the males, the amount of the metabolite M1 ( $N$-glycoside of ABZSO) rose with increasing ABZ concentrations in pre-incubation. On the other hand, the M1 formation in females was not affected by ABZ (Figure 7A).

The metabolite M2 ( $N$-glycoside of ABZSO) was found only in the $H$. contortus adults pre-incubated with ABZ, and it was not detected in any medium (Figure 7B). ABZSO represents the most abundant ABZ metabolite (M3) in both sexes of $H$. contortus (Figure 7C). Comparing control and ABZ-affected samples, concentrations of M3 did not differ with the exception of a M3 decrease in the female homogenates as well as the male medium pre-incubated with $1 \mu \mathrm{M}$ ABZ. The metabolite M4 ( $N$-glycoside of hydrolyzed ABZ) was formed only in the females. A much higher amount of M4 was detected in the medium than in the helminths (Figure 7D).
The pre-incubation of the $H$. contortus adults with ABZ at low concentrations significantly increased the amount of ABZ-sulfone (M6) in the homogenates and media from the females but not from males (Figure 7E). An increased amount of M7 ( $N$-glycoside of ABZ) was found in media from both sexes pre-incubated with $\mathrm{ABZ}$ at low concentrations (Figure 7F). A significant increase of the amount of M8 ( $N$-glycoside of ABZ) after pre-incubation was observed in medium from males as well as females (Figure 7G). The pre-incubation of females with $1 \mu \mathrm{M}$ ABZ led to a substantial increase of M9 $(N$-glycoside of $\mathrm{ABZ}$ ) in the homogenates (Figure $7 \mathrm{H}$ ). This metabolite was not detected in the control media, but the amounts significantly increased in the medium from the nematodes pre-incubated with $\mathrm{ABZ}$ at low concentrations. Pre-incubation significantly induced the formation of the metabolite M10 (acetylglycoside of ABZ) only in the medium from the females, and it increased the amount 


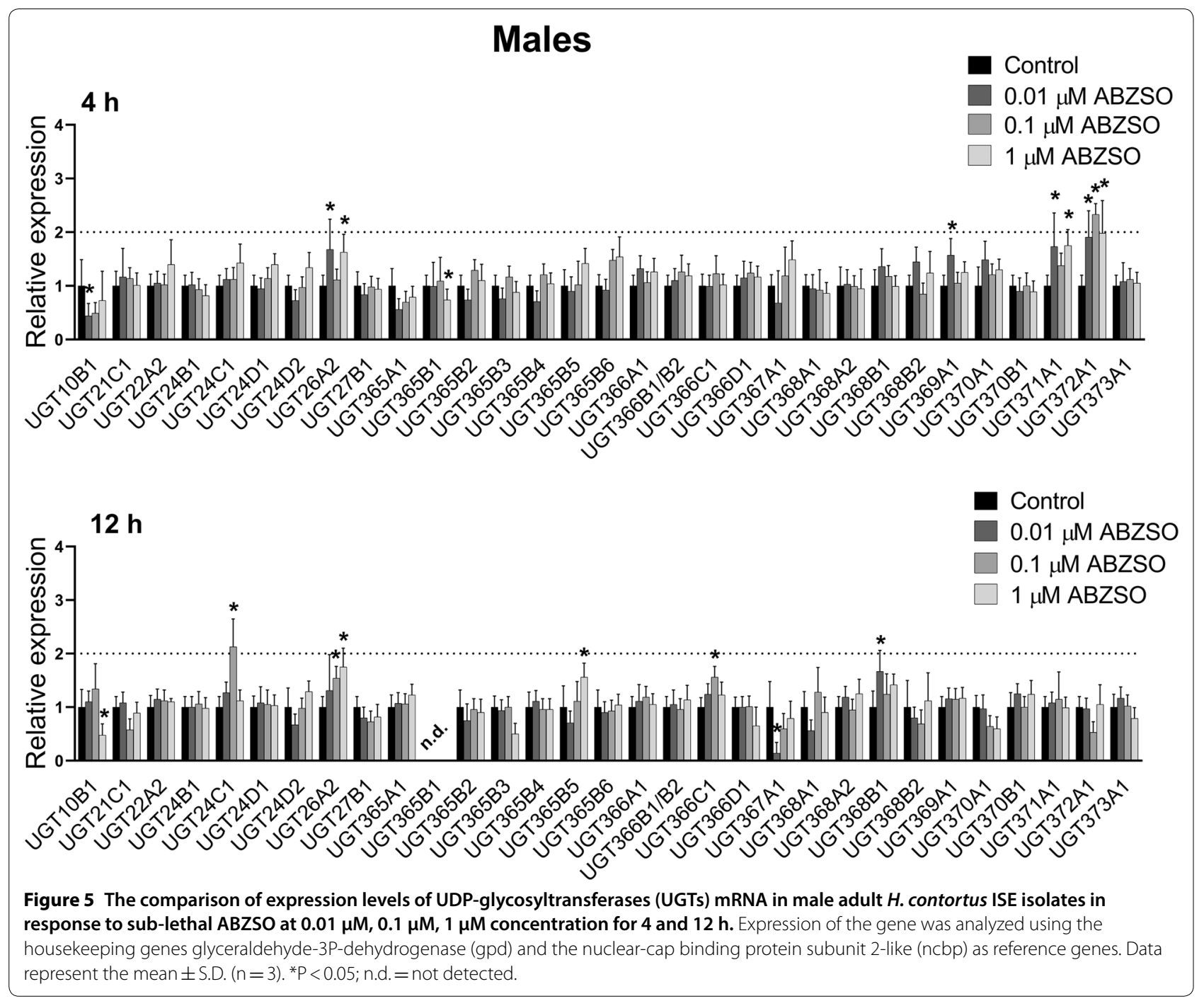

of the metabolite M11 (acetylglycoside of ABZ) in the males as well as in the females (Figures 7I, J). The minor metabolites M12 and M13 (acetylglycosides of ABZ) were female-specific, and they were detected only in the helminths pre-incubated with $\mathrm{ABZ}$ at low concentrations (Figures 7K, L).

\section{Discussion}

Contact of helminths with sub-lethal doses of anthelmintics may occur relatively often and under various circumstances, with the improper management of anthelmintic administration such as underdosage representing the main cause $[23,24]$. The appropriate dosage of drugs is an issue for most large animal farms. Even though that the treatment dosage should be adjusted to the heaviest animal from the flock [25], most farmers do not weigh all the animals, and therefore some of them are easily undertreated. Moreover, in some regions the drug is mixed into food, in which case many animals may not uptake a sufficient amount of the drug. In addition to dose, the available concentration of anthelmintic basically depends on drug absorption, distribution, metabolism and elimination, any of which might vary due to several factors e.g. animal species, breed, age, weight, sex and nutrition $[26,27]$. These factors along with others are key in terms of the insufficient concentration of the drug affecting the helminths. As several laboratory experiments have shown, sub-lethal doses of anthelmintics contribute to the selection of resistant or tolerant strains of parasites with single-nucleotide polymorphisms (SNPs) at the beta-tubulin 1 gene, which is considered a principal mechanism of $A B Z$ resistance in nematodes [24]. Nevertheless, a number of studies indicate the existence of other mechanisms of ABZ resistance, e.g. a recent study on the nematode Ancylostoma ceylanicum describing the preparation of ABZ-resistant strain without these 
Kellerová et al. Vet Res

(2020) $51: 94$

Page 10 of 17

ABY
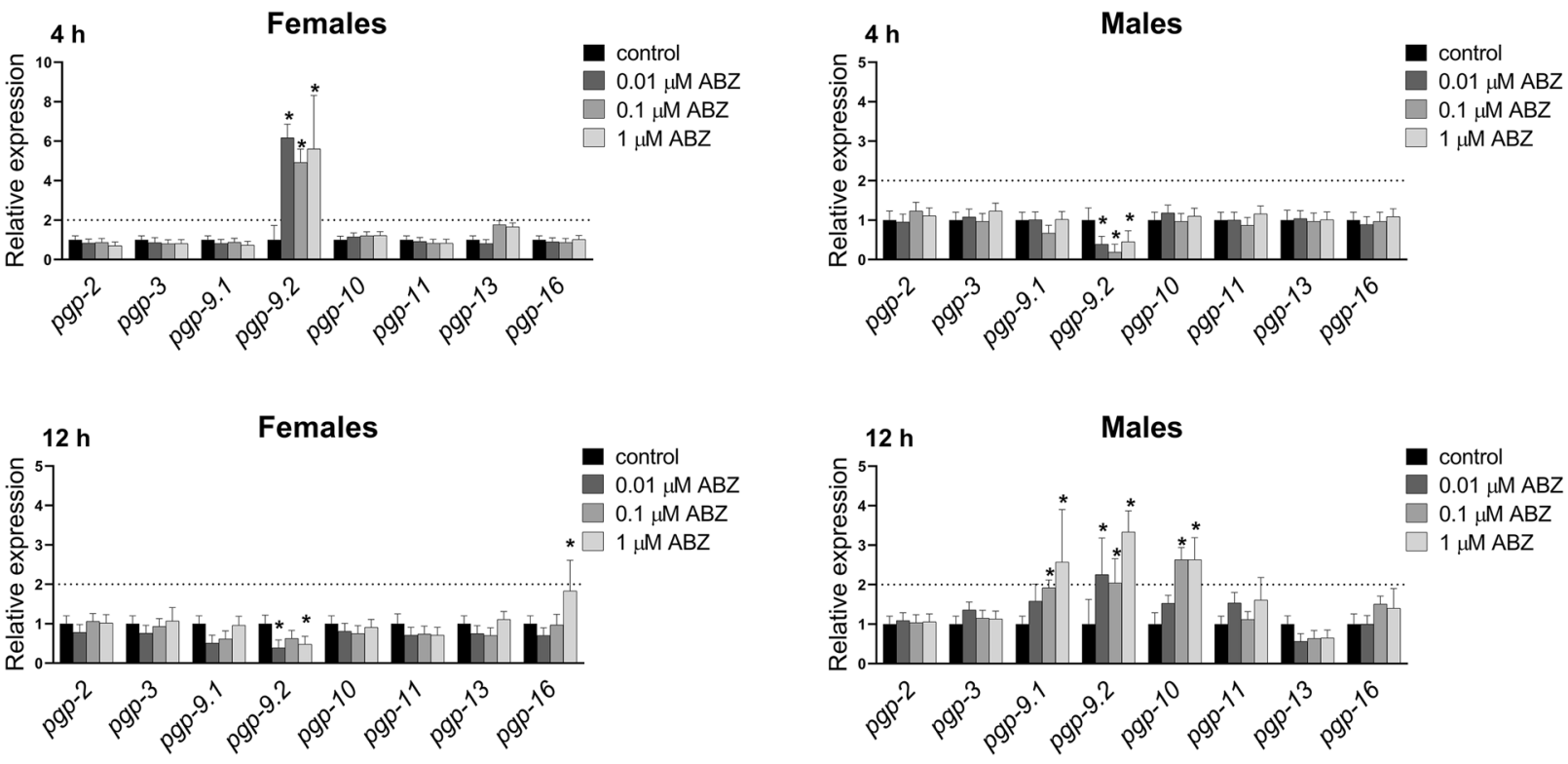

ABZSO
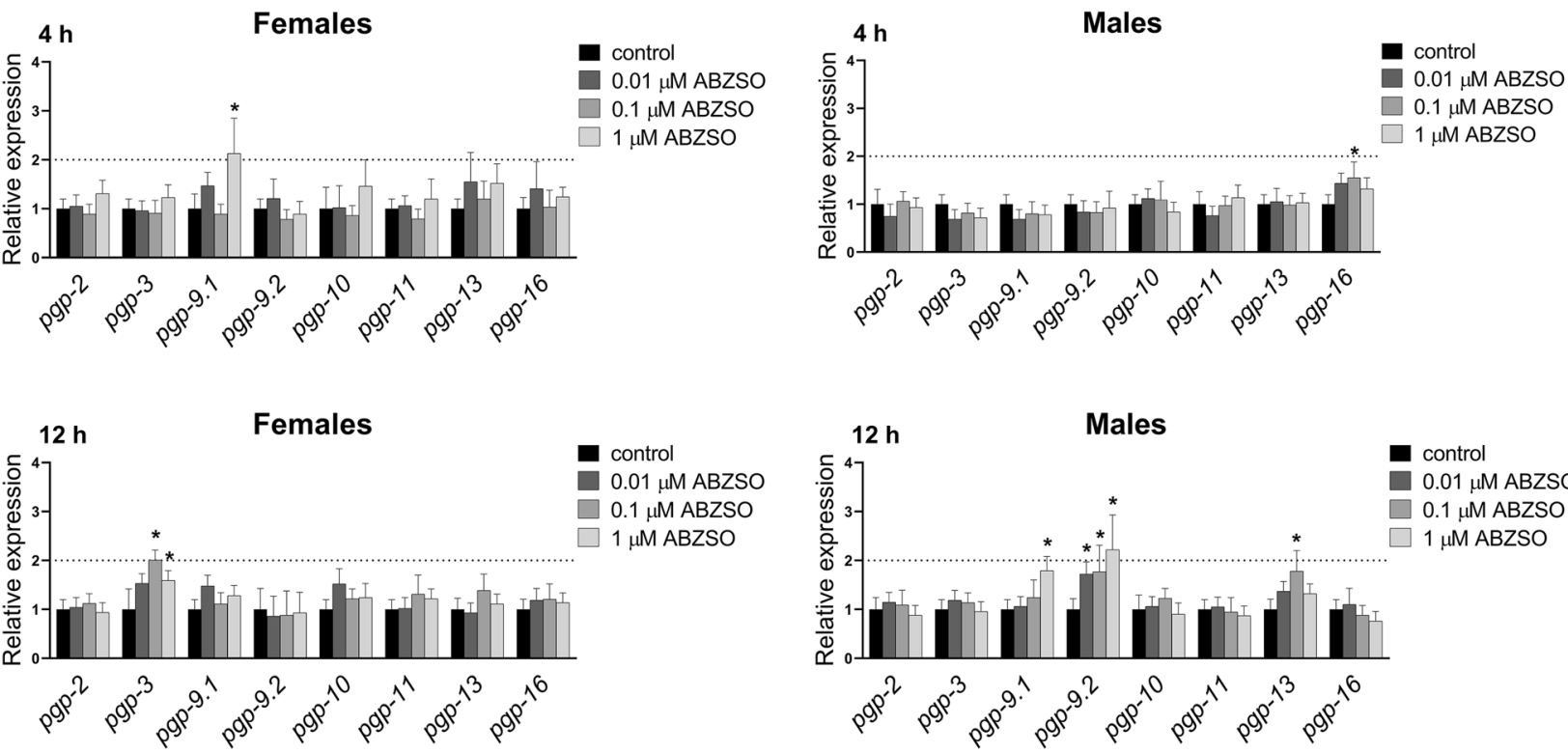

Figure 6 The comparison of expression levels of P-glycoproteins (P-gps) ERNA in female and male adult $H$. contortus ISE isolates in response to sublethal $A B Z$ and $A B Z S O$ at $0.01 \mu \mathrm{M}, 0.1 \mu \mathrm{M}, 1 \mu \mathrm{M}$ concentration for 4 and $12 \mathrm{~h}$. Expression of the gene was analyzed using the housekeeping genes glyceraldehyde-3P-dehydrogenase ( gad) and the nuclear-cap binding protein subunit 2-like (ncbp) as reference genes. Data represent the mean \pm STD. $(n=3)$. *P $<0.05$. 
Table 2 Biotransformation of ABZ in H. contortus adults - the metabolites detected by UHPLC-MS/MS

\begin{tabular}{|c|c|c|c|c|c|c|}
\hline \multirow[t]{2}{*}{$t_{R}(\min )$} & \multirow{2}{*}{$\begin{array}{l}\text { Theoretical } m / z \\
\text { values of }[M+H]^{+} \\
\text {ions }\end{array}$} & \multirow[t]{2}{*}{ Elemental composition } & \multicolumn{2}{|c|}{ Description of metabolite formation } & \multirow{2}{*}{$\begin{array}{l}\text { Product ions } \\
\text { of }[\mathrm{M}+\mathrm{H}]+, \mathrm{m} / \mathrm{z}\end{array}$} & \multirow[t]{2}{*}{ Metabolite designation } \\
\hline & & & Phase I & Phase II & & \\
\hline 2.0 & 444.14 & $\mathrm{C}_{18} \mathrm{H}_{25} \mathrm{~N}_{3} \mathrm{O}_{8} \mathrm{~S}$ & S-oxidation & N-glycosidation & $282,240,208$ & $M 1_{A B Z}$ \\
\hline 2.5 & 444.14 & $\mathrm{C}_{18} \mathrm{H}_{25} \mathrm{~N}_{3} \mathrm{O}_{8} \mathrm{~S}$ & S-oxidation & N-glycosidation & $282,240,208$ & $M 2_{A B Z}$ \\
\hline 3.4 & 282.09 & $\mathrm{C}_{12} \mathrm{H}_{15} \mathrm{~N}_{3} \mathrm{O}_{3} \mathrm{~S}$ & S-oxidation & - & $240,208,191,159$ & $M 3_{A B Z}$ \\
\hline 4.3 & 370.14 & $\mathrm{C}_{16} \mathrm{H}_{23} \mathrm{~N}_{3} \mathrm{O}_{5} \mathrm{~S}$ & Hydrolysis & N-glycosidation & 208 & $M 4_{A B Z}$ \\
\hline 5.2 & 298.09 & $\mathrm{C}_{12} \mathrm{H}_{15} \mathrm{~N}_{3} \mathrm{O}_{4} \mathrm{~S}$ & $2 *$ S-oxidation & - & $266,224,159$ & $M 6_{A B Z}$ \\
\hline 5.1 & 428.15 & $\mathrm{C}_{18} \mathrm{H}_{25} \mathrm{~N}_{3} \mathrm{O}_{7} \mathrm{~S}$ & - & N-glycosidation & 266,234 & $M 7_{A B Z}$ \\
\hline 5.1 & 428.15 & $\mathrm{C}_{18} \mathrm{H}_{25} \mathrm{~N}_{3} \mathrm{O}_{7} \mathrm{~S}$ & $+O$, hydrolysis & Glycosidation, O-acetylation & 208 & $\mathrm{M} 11_{\mathrm{ABZ}}$ \\
\hline 5.3 & 428.15 & $\mathrm{C}_{18} \mathrm{H}_{25} \mathrm{~N}_{3} \mathrm{O}_{7} \mathrm{~S}$ & $+O$, hydrolysis & Glycosidation, O-acetylation & 208 & $\mathrm{M} 12_{\mathrm{ABZ}}$ \\
\hline 5.6 & 428.15 & $\mathrm{C}_{18} \mathrm{H}_{25} \mathrm{~N}_{3} \mathrm{O}_{7} \mathrm{~S}$ & $+O$, hydrolysis & Glycosidation, O-acetylation & 208 & $M 13_{A B Z}$ \\
\hline 6.1 & 428.15 & $\mathrm{C}_{18} \mathrm{H}_{25} \mathrm{~N}_{3} \mathrm{O}_{7} \mathrm{~S}$ & $+O$, hydrolysis & Glycosidation, O-acetylation & 208 & $M 10_{A B Z}$ \\
\hline 6.1 & 428.15 & $\mathrm{C}_{18} \mathrm{H}_{25} \mathrm{~N}_{3} \mathrm{O}_{7} \mathrm{~S}$ & - & N-glycosidation & 266,234 & $M 8_{A B Z}$ \\
\hline 6.7 & 428.15 & $\mathrm{C}_{18} \mathrm{H}_{25} \mathrm{~N}_{3} \mathrm{O}_{7} \mathrm{~S}$ & - & N-glycosidation & 266,234 & $M 9_{A B Z}$ \\
\hline 7.4 & 266.10 & $\mathrm{C}_{12} \mathrm{H}_{15} \mathrm{~N}_{3} \mathrm{O}_{2} \mathrm{~S}$ & - & - & 234 & ABZ (parent drug) \\
\hline
\end{tabular}

Table 3 Presence $(+)$ or absence $(-)$ of individual ABZ metabolites (M1-M13) in homogenates and medium of $H$. contortus adults preincubated without $(0)$ or with $A B Z$ in sub-lethal doses $(0.01,0.1$ and $1 \mu \mathrm{M})$

\begin{tabular}{|c|c|c|c|c|c|c|c|c|c|c|c|c|c|c|c|c|}
\hline \multirow{3}{*}{$\begin{array}{l}\text { Metabolite } \\
\text { designation }\end{array}$} & \multicolumn{8}{|c|}{ Homogenate of $H$. contortus } & \multicolumn{8}{|c|}{ Medium } \\
\hline & \multicolumn{4}{|c|}{ Female } & \multicolumn{4}{|c|}{ Male } & \multicolumn{4}{|c|}{ Female } & \multicolumn{4}{|c|}{ Male } \\
\hline & 0 & 0.01 & 0.1 & 1 & 0 & 0.01 & 0.1 & 1 & 0 & 0.01 & 0.1 & 1 & 0 & 0.01 & 0.1 & 1 \\
\hline$M 1_{A B Z}$ & + & + & + & + & + & + & + & + & + & + & + & + & + & + & + & + \\
\hline$M 2_{A B Z}$ & - & + & + & + & - & - & - & + & - & - & - & - & - & - & - & - \\
\hline$M 3_{A B Z}$ & + & + & + & + & + & + & + & + & + & + & + & + & + & + & + & + \\
\hline$M 4_{A B Z}$ & - & - & + & + & - & - & - & - & + & + & + & + & - & - & + & + \\
\hline$M 6_{A B Z}$ & + & + & + & + & + & + & + & + & + & + & + & + & + & + & + & + \\
\hline$M 7_{A B Z}$ & + & + & + & + & + & + & + & + & + & + & + & + & + & + & + & + \\
\hline$M 8_{A B Z}$ & + & + & + & + & + & + & + & + & + & + & + & + & + & + & + & + \\
\hline$M 9_{A B Z}$ & + & + & + & + & + & + & + & + & - & + & + & + & - & + & + & + \\
\hline$M 10_{A B Z}$ & + & + & + & + & + & + & + & + & + & + & + & + & + & + & + & + \\
\hline$M 11_{\mathrm{ABZ}}$ & + & + & + & + & - & - & + & + & - & + & + & + & - & - & + & + \\
\hline$M 12_{\mathrm{ABZ}}$ & - & + & + & + & - & - & - & - & - & + & + & + & - & - & - & - \\
\hline$M 13_{A B Z}$ & - & - & + & + & - & - & - & - & - & - & - & + & - & - & - & - \\
\hline$A B Z$ & + & + & + & + & + & + & + & + & + & + & + & + & + & + & + & + \\
\hline
\end{tabular}

SNPs. [28] The induction of drug-metabolizing enzymes (DMEs) might represent one of these mechanisms.

Although induced expression of certain DMEs in resistant isolates in comparison to sensitive ones has been reported repeatedly $[5,6,12,14]$, the mechanisms and circumstances of this induction have not been elucidated. As the contact of nematodes with sub-lethal doses of anthelmintics may play an important role, we incubated ex vivo $H$. contortus adults from ISE strain (sensitive to all anthelmintics) with the anthelmintic drug albendazole (ABZ) and its active metabolite ABZ-sulfoxide (ABZSO) at three sub-lethal doses for 4 and $12 \mathrm{~h}$. Two different incubation duration were used because it is known that the time required to induce different DMEs differs significantly [29]. The expression levels of individual CYPs, UGTs and P-gps were quantified and compared to levels in controls (exposed to solvent only). We focused on these DMEs, as they have been considered to be key enzymes responsible for $\mathrm{ABZ}$ and $\mathrm{ABZSO}$ metabolism in H. contortus [10].

CYPs are key biotransformation enzymes catalyzing the oxidation of drugs and other xenobiotics in all 


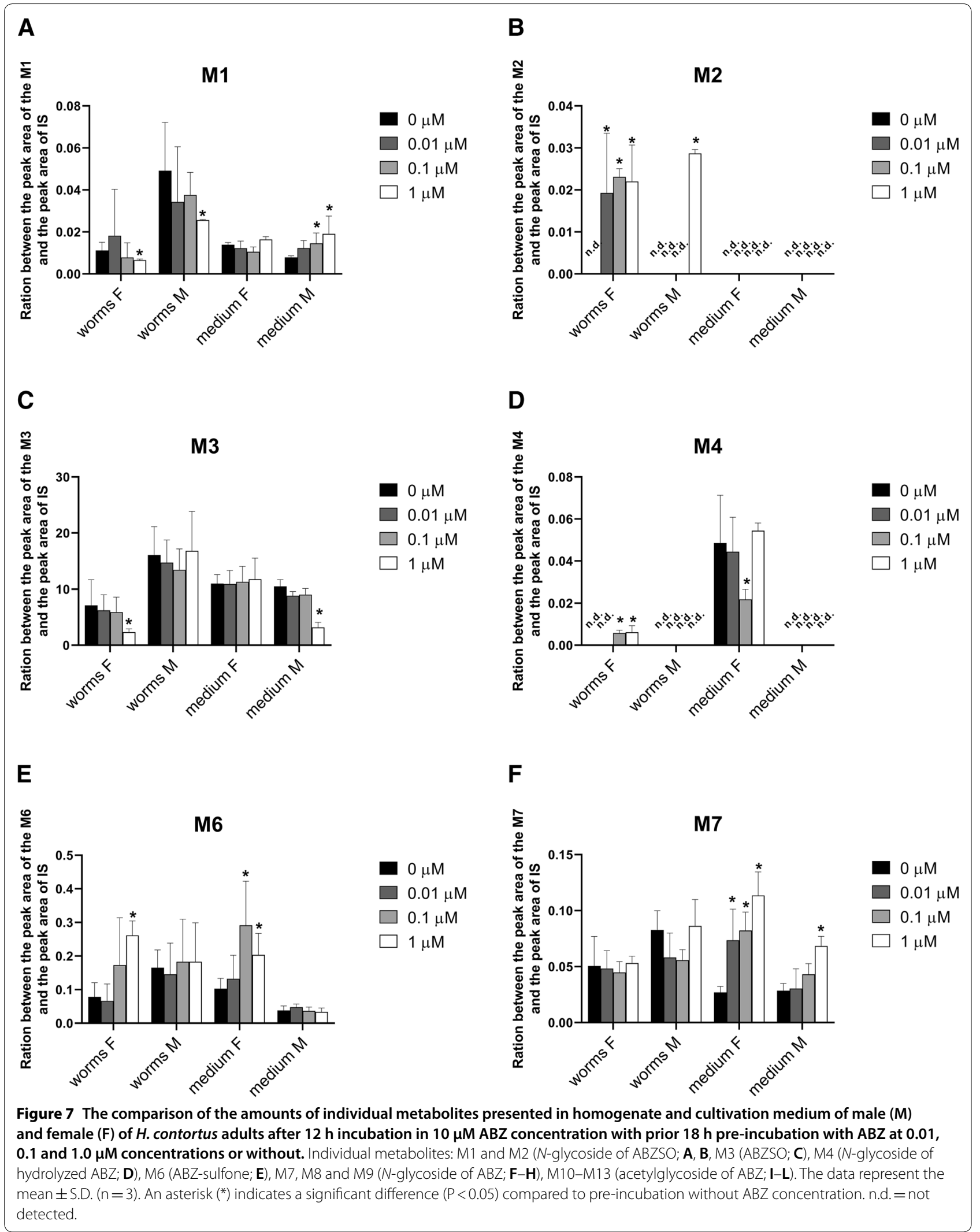




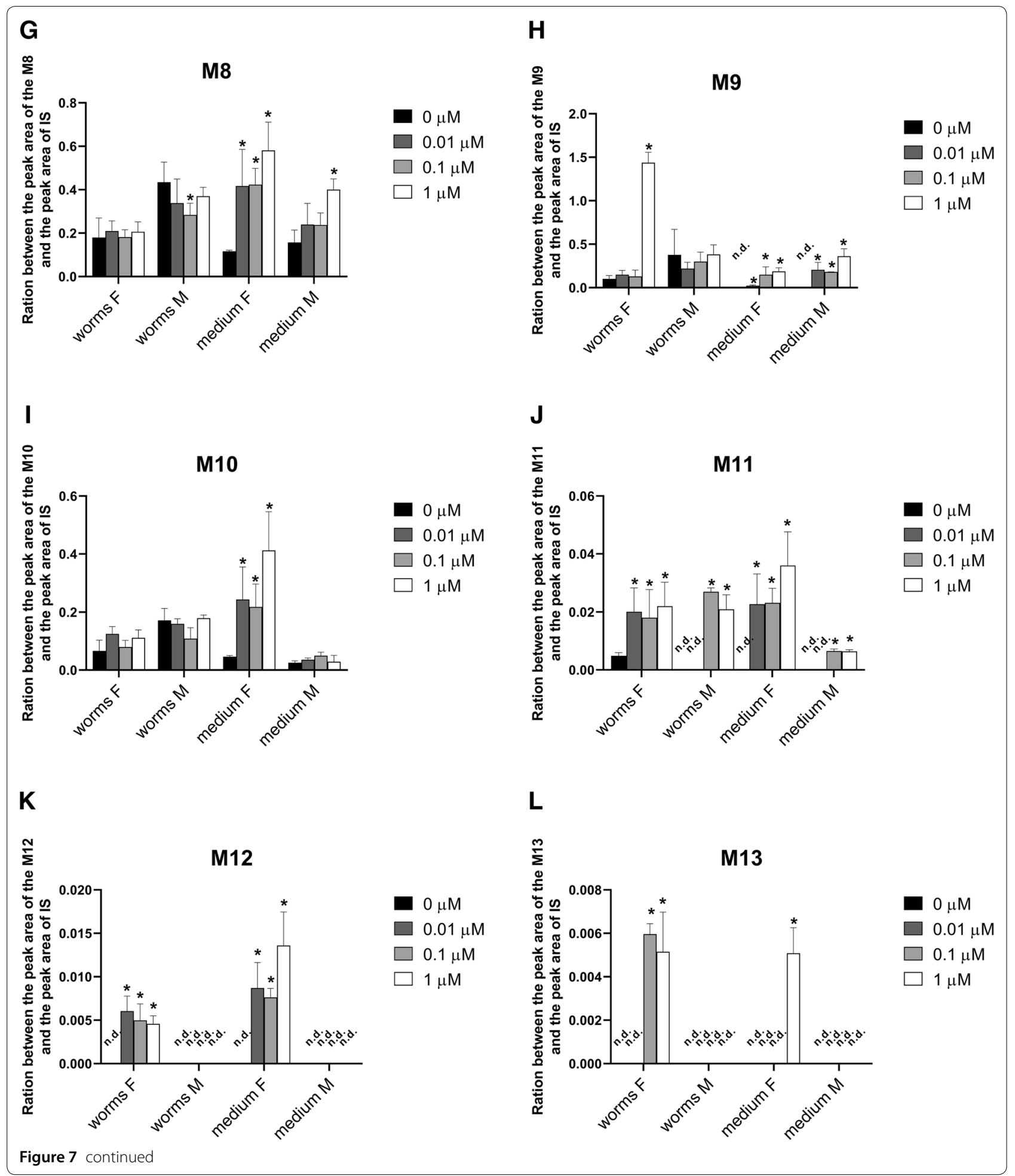

organisms, with $S$-oxidation representing the main metabolic transformation mechanism of ABZ and ABZSO in $H$. contortus adults. For these reasons, the expression levels of 8 individual CYPs in control adults (females and males separately) and in adults exposed to sub-lethal concentrations of $\mathrm{ABZ}$ and ABZSO for 4 and $12 \mathrm{~h}$ were analyzed and compared. The exposures of $H$. contortus adults to sub-lethal ABZ concentrations significantly 


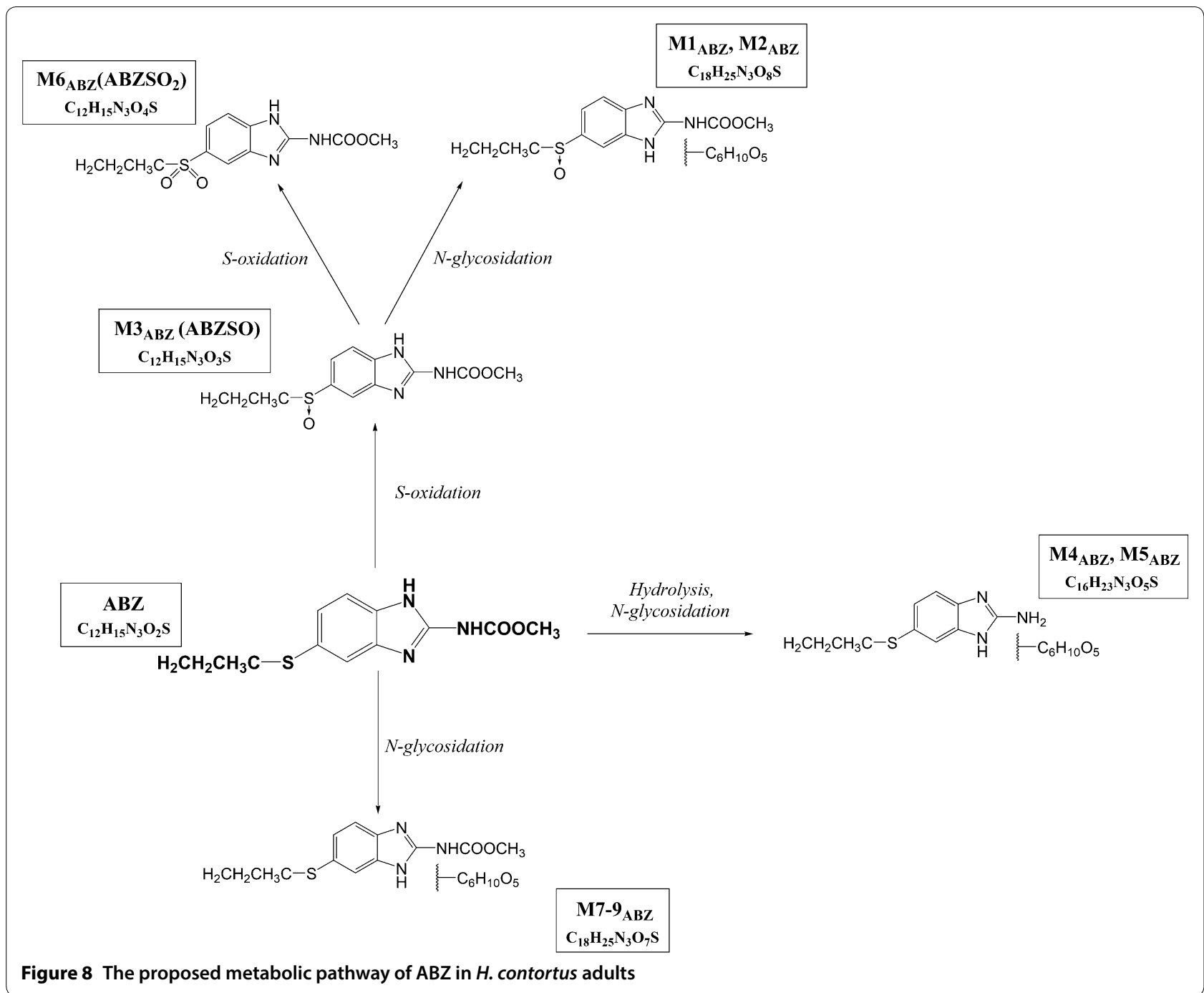

changed the mRNA expression of only three of the studied CYPs, Cyp-2 in females, cyp-3 and cyp-7 in males. Sub-lethal doses of ABZSO affected expression of more CYP genes then did ABZ. However, the induction effect was mild and only at the higher concentration in most cases.

In a previous study of ours, $H$. contortus adults were exposed to sub-lethal doses of ivermectin (IVM). In females, no significant changes in the transcription profile of CYPs were observed except for cyp-7, which was significantly up-regulated after $12 \mathrm{~h}$ exposure time. In the males, three genes were significantly increased: cyp-1, cyp-3, and cyp-5 [30]. Comparing the effect of ABZ and ABZSO, IVM had the same effect as ABZ in females (upregulation only of $c y p-7)$. Both $\mathrm{ABZ}$ and IVM increased transcription of cyp-3 in males. However, ABZSO induced completely different CYP genes than did ABZ and IVM, probably due to higher hydrophilicity. On the other hand, no CYP genes were induced by thiabendazole $(2.5 \mu \mathrm{M})$ exposure for 3 and $6 \mathrm{~h}$ in $H$. contortus larvae [31].

Besides the CYPs, we focused also on UGTs. The association of UGTs with resistance to several drug classes has been shown in human therapy [32, 33]. Recently, UGTs have been considered key players in insecticide resistance [34]. In $H$. contortus, 32 UGTs are present [12], and the formation of glycosides is the main metabolic pathway of ABZ as well as ABZSO in $H$. contortus adults. Moreover, resistant isolates formed many more ABZand ABZSO-glycosides than did the susceptible ones [10]. In the present study, we analyzed the expression of UGT genes in control nematodes and in nematodes exposed to sub-lethal concentrations of ABZ and ABZSO for 4 and $12 \mathrm{~h}$. In females, ABZ exposure elevated expression of three and two UGTs after 4 and 12-h, respectively. Interestingly, $\mathrm{ABZ}$ at all three concentrations 
and both time intervals showed substantially and highly elevated UGT367A1 expression in the females (>4-fold). In the males, expression of seven UGT genes were upregulated after $\mathrm{ABZ}$ exposure. Among them, UGT26A2 seems to be the most interesting, as ABZ at all concentrations increased its expression. Induction of UGT1OB1 in females was the most pronounced, occurring at all $\mathrm{ABZSO}$ concentrations. In the males, ABZSOinduced overexpression of four UGTs was detected, with UGT372A1 being the most elevated after 4-h exposure. Interestingly, the $\mathrm{ABZ}$ or ABZSO exposure in our study evaluated two UGTs (UGT368B2, UGT372A1) in both genders which were also increased in resistant (IRE) and multi-resistant (WR) strains of $H$. contortus for both genders in comparison to the susceptible (ISE) strain [12]. Furthermore, increased constitutive expression of another UGT (UGT366A1) in the females as well as three other UGTs (UGT26A2, UGT371A1, UGT368B1) in the males in both resistant strains in comparison to the sensitive strain was reported, suggesting possible contribution to xenobiotics deactivation [12].

In model nematodes Caenorhabditis elegans, ugt-22 (UGT16C1) was identified as a detoxification enzyme influencing $\mathrm{ABZ}$ efficacy. Mutation and overexpression of the ugt-22 gene altered $\mathrm{ABZ}^{\mathrm{E} C} \mathrm{C}_{50}$ by 2.3- to 2.5fold [35]. When C. elegans adults of the resistant strain CB3474 ben-1(e1880) III were exposed to ABZ and other benzimidazole anthelmintics (mebendazole, thiabendazole, and oxfendazole), the up-regulation of UGT genes (ugt-14/25/33/34/37/41/8/9) was observed. Surprisingly, the transcriptional xenobiotic response of $H$. contortus adults from the resistant strain UGA/2004 to anthelmintics exposure was undetectable [36]. Nevertheless, this discrepancy is probably based on the very high (lethal) concentrations $(1.13 \mathrm{mM})$ of anthelmintics used in mentioned study.

In addition to CYPs and UGTs, the effect of ABZ and ABZSO on expression of efflux transporters P-glycoproteins (P-gps) was also studied as P-gps have been implicated in the multidrug resistance of different parasitic nematodes in livestock [14]. Although the increased transcription of P-gps has been mainly associated with resistance to IVM and other macrocyclic lactones [37, 38], the participation of P-gps in ABZ resistance cannot be excluded. In our study, exposure to ABZ and ABZSO affected transcription levels of six (out of eight tested) transporter genes in H. contortus adults. However, IVMinduced changes in P-gps expression were more pronounced; particularly the expression of $p g p-9.2$ in the males and pgp-10, pgp-11 in the females was increased substantially [30], a result which is in agreement with the clear relationship of P-gps with IVM metabolism and resistance in nematodes $[39,40]$. Nevertheless, increased transcription of several P-gps after ABZ and ABZSO exposure suggests a particular role of these transporters in the metabolism of these drugs as well.

With the aim of determining whether DMEs induction really improves the ability to deactivate $\mathrm{ABZ}$ during consequent exposure, the metabolism of $\mathrm{ABZ}$ was compared in control nematodes and in nematodes pre-incubated with a sub-lethal ABZ dose. UHPLC/MS analyses revealed that $H$. contortus adults metabolized ABZ via S-oxidation or hydroxylation, hydrolysis and glycosidation followed by $O$-acetylation. All the metabolites can be considered as deactivation products with exception of ABZSO, which is anthelmintically active (and marketed as ricobendazole). Twelve $\mathrm{ABZ}$ metabolites were found in $H$. contortus adults pre-incubated with ABZ, while only nine metabolites were detected in the control population. These nine metabolites were identified and characterized in our previous study of ABZ metabolism in $H$. contortus adults [10]. In our present study, the increased formation of several metabolites ( $\mathrm{ABZSO}_{2}$ and various glycosides) was found in the adults which were exposed to sub-lethal doses of ABZ. The finding that all the metabolites with increased production can be considered a deactivation product underscores the importance of this process for improving tolerance to ABZ. Moreover, the results of our functional study are in an excellent agreement with our transcriptional study: the expression levels of some CYPs (probably catalyzing ABZ oxidation), several UGTs (catalyzing $\mathrm{ABZ}$ and ABZSO glycosidation) and P-gps (exporting ABZ metabolites from helminths' bodies) were elevated in the nematodes exposed to sub-lethal doses of ABZ. In particular, the up-regulation of UGTs (UGT10B1, UGT365A1, UGT367A1, UGT368B2) in combination with the increased formation of nine glycosylated metabolites provides promising results in terms of considering UGTs as anthelmintic resistance mediators. Nevertheless, the evaluation of the role of individual UGTs in ABZ metabolism will require further study. In addition to UGTs, other DMEs in $H$. contortus require further attention, as hydrolases and acetylases also take part in ABZ metabolism, and no information about these enzymes is available.

Even though the parent drug of ABZ is considered neither a substrate nor an inhibitor of P-gps [41], a statistically significant interaction between ABZ metabolites and drug efflux inhibitors were presented in sheep and rats [42]. In our study we clearly showed that both $A B Z$ and ABZSO can induce more than half of the P-gp genes studied. Moreover, a significant increase was shown in the efflux of eight metabolites, a finding which verifies the higher activity of transporters after contact with sublethal $\mathrm{ABZ}$ concentrations; this likewise suggests that ABZ biotransformation products are better substrates for 
efflux pumps than ABZ itself. This supports the hypothesis that P-gps do play a significant role for $H$. contortus resistance, not only for ivermectin [43, 44], but probably for other anthelmintic drugs including levamisole, monepantel $[45,46]$ and also ABZ.

In conclusion, the presented study demonstrates for the first time that contact of $H$. contortus adults with sub-lethal doses of ABZ leads to the induction of several drug-metabolizing enzymes, particularly UGTs, and to a lesser extent CYPs and P-gps. This induction improved the ability of $H$. contortus adults to deactivate $\mathrm{ABZ}$ in consequent therapy via the increased formation of inactive metabolites (namely ABZ-sulfone and various glycosides) and their export from the helminths' body. In this way, the contact of $H$. contortus with sub-lethal doses of ABZ could allow parasites to survive pharmacotherapy.

\section{Supplementary information}

Supplementary information accompanies this paper at https://doi. org/10.1186/s13567-020-00820-x.

Additional file 1. The sequences, amplicon sizes, and efficiencies of primers.

\section{Abbreviations}

ABZ: albendazole; ABZSO: albendazole sulfoxide; CYP: cytochrome P450; IS: internal standard; ISE: inbred susceptible-Edinburgh strain (MHco3); P-gp: P-glycoprotein; UGT: UDP-glycosyltransferase.

\section{Acknowledgements}

We would like to thank Prof. Marián Várady of the Institute of Parasitology, Slovak Academy of Sciences for providing H. contortus larvae, and Daniel Sampey, MFA for the English revision.

\section{Authors' contributions}

LS designed and controlled the project. PK, PM and KŠ performed and evaluated all experiments of the transcriptional study. LRS, MN and IV performed and evaluated all experiments in the functional study. JL, PK and BS infected animals, isolated and cultivated helminths. PK, LRS and LS wrote manuscript. PM and BS revised manuscript. All authors read and approved the final manuscript.

\section{Funding}

This work was supported by the Czech Science Foundation, grant No. 18-07724S and by Charles University in Prague, projects PRIMUS/17/SCI/4, UNCE/18/SCI/012 and SWV 260,550 as well as by the project EFSA-CDN [CZ.02. 1.01/0.0/0.0/16_019/0000841], co-funded by ERDF.

\section{Availability of data and materials}

The datasets supporting the conclusions of this article are included within the article and its additional files.

\section{Ethics approval}

All experiments with animals were performed according to the protocols evaluated and approved by the Ethics Committee of the Ministry of Education, Youth and Sports of the Czech Republic (Protocol MSMT-25908/2014-9).

\section{Consent to publish}

All authors read and approved the manuscript and they agreed with publication.

\section{Competing interests}

The authors declare that they have no competing interests.

\section{Author details}

${ }^{1}$ Department of Biochemical Sciences, Faculty of Pharmacy, Charles University, Heyrovského 1203, 50005 Hradec Králové, Czech Republic. ${ }^{2}$ Department of Pharmacology and Toxicology, Faculty of Pharmacy, Charles University, Heyrovského 1203, Hradec Králové, Czech Republic.

Received: 10 March 2020 Accepted: 16 July 2020

Published online: 23 July 2020

\section{References}

1. Emery DL, Hunt PW, Le Jambre LF (2016) Haemonchus contortus: the then and now, and where to from here? Int J Parasitol 46:755-769

2. Khan S, Zhao XC, Hou YN, Yuan CX, Li YM, Luo XP, Liu JZ, Feng XG (2019) Analysis of genome-wide SNPs based on $2 b-R A D$ sequencing of pooled samples reveals signature of selection in different populations of Haemonchus contortus. J Biosci 44:97

3. Teixeira M, Matos A, Albuquerque F, Bassetto CC, Smith WD, Monteiro JP (2019) Strategic vaccination of hair sheep against Haemonchus contortus. Parasitol Res 118:2383-2388

4. Ruano ZM, Carolino N, Mateus TL (2017) Gastrointestinal parasites as a threat to grazing sheep. Large Anim Rev 23:231-238

5. Lanusse C, Canton C, Virkel G, Alvarez L, Costa L, Lifschitz A (2018) Strategies to optimize the efficacy of anthelmintic drugs in ruminants. Trends Parasitol 34:664-682

6. Matoušková P, Vokřál I, Lamka J, Skálová L (2016) The role of xenobioticmetabolizing enzymes in anthelmintic deactivation and resistance in helminths. Trends Parasitol 32:481-491

7. Stuchlikova L, Jirasko R, Vokral I, Valat M, Lamka J, Szotakova B, Holcapek M, Skalova L (2014) Metabolic pathways of anthelmintic drug monepantel in sheep and in its parasite (Haemonchus contortus). Drug Test Anal 6:1055-1062

8. Vokral I, Jirasko R, Stuchlikova L, Bartikova H, Szotakova B, Lamka J, Varady M, Skalova $L$ (2013) Biotransformation of albendazole and activities of selected detoxification enzymes in Haemonchus contortus strains susceptible and resistant to anthelmintics. Vet Parasitol 196:373-381

9. Vokral I, Bartikova H, Prchal L, Stuchlikova L, Skalova L, Szotakova B, Lamka J, Varady M, Kubicek V (2012) The metabolism of flubendazole and the activities of selected biotransformation enzymes in Haemonchus contortus strains susceptible and resistant to anthelmintics. Parasitology 139:1309-1316

10. Stuchlikova LR, Matouskova P, Vokral I, Lamka J, Szotakova B, Seckarova A, Dimunova D, Nguyen LT, Varady M, Skalova L (2018) Metabolism of albendazole, ricobendazole and flubendazole in Haemonchus contortus adults: sex differences, resistance-related differences and the identification of new metabolites. Int J Parasitol Drugs Drug Resist 8:50-58

11. Laing R, Bartley DJ, Morrison AA, Rezansoff A, Martinelli A, Laing ST, Gilleard JS (2015) The cytochrome P450 family in the parasitic nematode Haemonchus contortus. Int J Parasitol 45:243-251

12. Matouskova P, Lecova L, Laing R, Dimunova D, Vogel H, Stuchlikova LR, Nguyen LT, Kellerova P, Vokral I, Lamka J, Szotakova B, Varady M, Skalova L (2018) UDP-glycosyltransferase family in Haemonchus contortus: phylogenetic analysis, constitutive expression, sex-differences and resistancerelated differences. Int J Parasitol Drugs Drug Resist 8:420-429

13. Leprohon P, Legare D, Ouellette M (2011) ABC transporters involved in drug resistance in human parasites. Essays Biochem Abc Transp 50:121-144

14. Mate L, Ballent M, Canton C, Ceballos L, Lifschitz A, Lanusse C, Alvarez L, Liron JP (2018) Assessment of P-glycoprotein gene expression in adult stage of Haemonchus contortus in vivo exposed to ivermectin. Vet Parasitol 264:1-7

15. Roos MH, Otsen M, Hoekstra R, Veenstra JG, Lenstra JA (2004) Genetic analysis of inbreeding of two strains of the parasitic nematode Haemonchus contortus. Int J Parasitol 34:109-115

16. Vanwyk JA, Gerber HM, Groeneveld HT (1980) A technique for the recovery of nematodes from ruminants by migration from gastrointestinal ingesta gelled in agar-large scale application. Onderstepoort J Vet Res 47:147-158

17. Cvilink V, Skalova L, Szotakova B, Lamka J, Kostiainen R, Ketola RA (2008) LC-MS-MS identification of albendazole and flubendazole 
metabolites formed ex vivo by Haemonchus contortus. Anal Bioanal Chem 391:337-343

18. Livak KJ, Schmittgen TD (2001) Analysis of relative gene expression data using real-time quantitative PCR and the 2(T)(-Delta Delta C) method. Methods 25:402-408

19. Lecova L, Ruzickova M, Laing R, Vogel H, Szotakova B, Prchal L, Lamka J, Vokral I, Skalova L, Matouskova P (2015) Reliable reference gene selection for quantitative real time PCR in Haemonchus contortus. Mol Biochem Parasitol 201:123-127

20. Untergasser A, Cutcutache I, Koressaar T, Ye J, Faircloth BC, Remm M, Rozen SG (2012) Primer3-new capabilities and interfaces. Nucleic Acids Res 40:e115

21. Zuker M (2003) Mfold web server for nucleic acid folding and hybridization prediction. Nucleic Acids Res 31:3406-3415

22. Stuchlikova L, Jirasko R, Vokral I, Lamka J, Spulak M, Holcapek M, Szotakova B, Bartikova H, Pour M, Skalova L (2013) Investigation of the metabolism of monepantel in ovine hepatocytes by UHPLC/MS/MS. Anal Bioanal Chem 405:1705-1712

23. Leathwick DM, Besier RB (2014) The management of anthelmintic resistance in grazing ruminants in Australasia-strategies and experiences. Vet Parasitol 204:44-54

24. Shalaby HA (2013) Anthelmintics resistance; how to overcome it? Iran J Parasitol 8:18-32

25. Lawrence KE, Lethwick DM, Rhodes AP, Jackson R, Heuer C, Pomroy WE, West DM, Waghorn TS, Moffat JR (2007) Management of gastrointestinal nematode parasites on sheep farms in New Zealand. N Z Vet J 55:228-234

26. Aksit D, Yalinkilinc HS, Sekkin S, Boyacioglu M, Cirak VY, Ayaz E, Gokbulut C (2015) Comparative pharmacokinetics and bioavailability of albendazole sulfoxide in sheep and goats, and dose-dependent plasma disposition in goats. BMC Vet Res 11:124

27. Canga AG, Prieto AMS, Liebana MJD, Martinez NF, Vega MS, Vieitez JJG (2009) The pharmacokinetics and metabolism of ivermectin in domestic animal species. Vet J 179:25-37

28. Furtado LFV, De Aguiar PHN, Zuccherato LW, Teixeira TTG, Alves WP, Da Silva VJ, Gasser RB, Rabelo EML (2019) Albendazole resistance induced in Ancylostoma ceylanicum is not due to single-nucleotide polymorphisms (SNPs) at codons 167, 198, or 200 of the beta-tubulin gene, indicating another resistance mechanism. Parasitol Res 118:837-849

29. Lnenickova K, Skalova L, Raisova LS, Szotakova B, Matouskova P (2018) Induction of xenobiotic-metabolizing enzymes in hepatocytes by beta-naphthoflavone: time-dependent changes in activities, protein and mRNA levels. Acta Pharm 68:75-85

30. Kellerova P, Matouskova P, Lamka J, Vokral I, Szotakova B, Zajickova M, Pasak M, Skalova L (2019) Ivermectin-induced changes in the expression of cytochromes P450 and efflux transporters in Haemonchus contortus female and male adults. Vet Parasitol 273:24-31

31. Yilmaz E, Ramunke S, Demeler J, Krucken J (2017) Comparison of constitutive and thiabendazole-induced expression of five cytochrome P450 genes in fourth-stage larvae of Haemonchus contortus isolates with different drug susceptibility identifies one gene with high constitutive expression in a multi-resistant isolate. Int J Parasitol Drugs Drug Resist 7:362-369

32. Mazerska Z, Mroz A, Pawlowska M, Augustin E (2016) The role of glucuronidation in drug resistance. Pharmacol Ther 159:35-55

33. Verma H, Bahia MS, Choudhary S, Singh PK, Silakari O (2019) Drug metabolizing enzymes-associated chemo resistance and strategies to overcome it. Drug Metab Rev 51:196-223
34. Chen XW, Tang CY, Ma KS, Xia J, Song DL, Gao XW (2020) Overexpression of UDP-glycosyltransferase potentially involved in insecticide resistance in Aphis gossypii Glover collected from Bt cotton fields in China. Pest Manag Sci 76:371-377

35. Fontaine P, Choe K (2018) The transcription factor SKN-1 and detoxification gene ugt-22 alter albendazole efficacy in Caenorhabditis elegans. Int J Parasitol Drugs Drug Resist 8:312-319

36. Stasiuk SJ, Macnevin G, Workentine ML, Gray D, Redman E, Bartley D, Morrison A, Sharma N, Colwell D, Ro DK, Gilleard JS (2019) Similarities and differences in the biotransformation and transcriptomic responses of Caenorhabditis elegans and Haemonchus contortus to five different benzimidazole drugs. Int J Parasitol Drugs Drug Resist 11:13-29

37. Peachey LE, Pinchbeck GL, Matthews JB, Burden FA, Lespine A, Von Samson-Himmelstjerna G, Krucken J, Hodgkinson JE (2017) P-glycoproteins play a role in ivermectin resistance in cyathostomins. Int J Parasitol Drugs Drug Resist 7:388-398

38. Turnbull F, Jonsson NN, Kenyon F, Skuce PJ, Bisset SA (2018) P-glycoprotein-9 and macrocyclic lactone resistance status in selected strains of the ovine gastrointestinal nematode, Teladorsagia circumcincta. Int J Parasitol Drugs Drug Resist 8:70-80

39. Godoy P, Che H, Beech RN, Prichard RK (2016) Characterisation of P-glycoprotein-91 in Haemonchus contortus. Parasites Vectors 9:1

40. David M, Lebrun C, Duguet T, Talmont F, Beech R, Orlowski S, Andre F, Prichard RK, Lespine A (2018) Structural model, functional modulation by ivermectin and tissue localization of Haemonchus contortus P-glycoprotein-13. Int J Parasitol Drugs Drug Resist 8:145-157

41. Merino G, Alvarez Al, Prieto JG, Kim RB (2002) The anthelminthic agent albendazole does not interact with p-glycoprotein. Drug Metab Dispos 30:365-369

42. Merino G, Molina AJ, Garcia JL, Pulido MM, Prieto JG, Alvarez Al (2003) Intestinal elimination of albendazole sulfoxide: pharmacokinetic effects of inhibitors. Int J Pharm 263:123-132

43. Lespine A, Menez C, Bourguinat C, Prichard RK (2012) P-glycoproteins and other multidrug resistance transporters in the pharmacology of anthelmintics: prospects for reversing transport-dependent anthelmintic resistance. Int J Parasitol Drugs Drug Resist 2:58-75

44. Menez C, Alberich M, Kansoh D, Blanchard A, Lespine A (2016) Acquired tolerance to ivermectin and moxidectin after drug selection pressure in the nematode Caenorhabditis elegans. Antimicrob Agents Chemother 60:4809-4819

45. Raza A, Bagnall NH, Jabbar A, Kopp SR, Kotze AC (2016) Increased expression of ATP binding cassette transporter genes following exposure of Haemonchus contortus larvae to a high concentration of monepantel in vitro. Parasit Vectors 9:522

46. Raza A, Kopp SR, Bagnall NH, Jabbar A, Kotze AC (2016) Effects of in vitro exposure to ivermectin and levamisole on the expression patterns of $A B C$ transporters in Haemonchus contortus larvae. Int J Parasitol Drugs Drug Resist 6:103-115

\section{Publisher's Note}

Springer Nature remains neutral with regard to jurisdictional claims in published maps and institutional affiliations.

Ready to submit your research? Choose BMC and benefit from:

- fast, convenient online submission

- thorough peer review by experienced researchers in your field

- rapid publication on acceptance

- support for research data, including large and complex data types

- gold Open Access which fosters wider collaboration and increased citations

- maximum visibility for your research: over $100 \mathrm{M}$ website views per year

At BMC, research is always in progress.

Learn more biomedcentral.com/submissions 